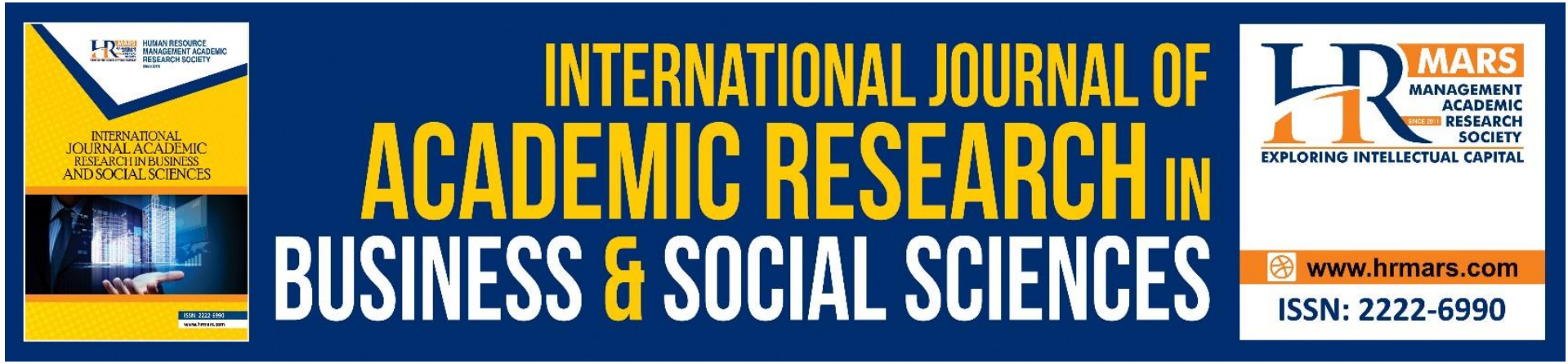

\title{
Exploratory Factor Analysis in Teacher Questioning Elements for Critical Thinking among form 4 Students in Some Selected Schools in the State of Sarawak
}

Arshad Jais, Noraffandy Yahaya, Nor Hasniza Ibrahim, Nazeri Bin Mohammad

To Link this Article: http://dx.doi.org/10.6007/IJARBSS/v11-i8/10743 DOI:10.6007/IJARBSS/v11-i8/10743

Received: 21 June 2021, Revised: 23 June 2021, Accepted: 14 July 2021

Published Online: 26 August 2021

In-Text Citation: (Jais et al., 2021)

To Cite this Article: Jais, A., Yahaya, N., Ibrahim, N. H., \& Mohammad, N. Bin. (2021). Exploratory Factor Analysis in Teacher Questioning Elements for Critical Thinking among form 4 Students in Some Selected Schools in the State of Sarawak. International Journal of Academic Research in Business and Social Sciences, 11(8), 1901-1910.

\section{Copyright: (c) 2021 The Author(s)}

Published by Human Resource Management Academic Research Society (www.hrmars.com) This article is published under the Creative Commons Attribution (CC BY 4.0) license. Anyone may reproduce, distribute, translate and create derivative works of this article (for both commercial and non-commercial purposes), subject to full attribution to the original publication and authors. The full terms of this license may be seen at: http://creativecommons.org/licences/by/4.0/legalcode

Vol. 11, No. 8, 2021, Pg. 1901 - 1910

Full Terms \& Conditions of access and use can be found at http://hrmars.com/index.php/pages/detail/publication-ethics 


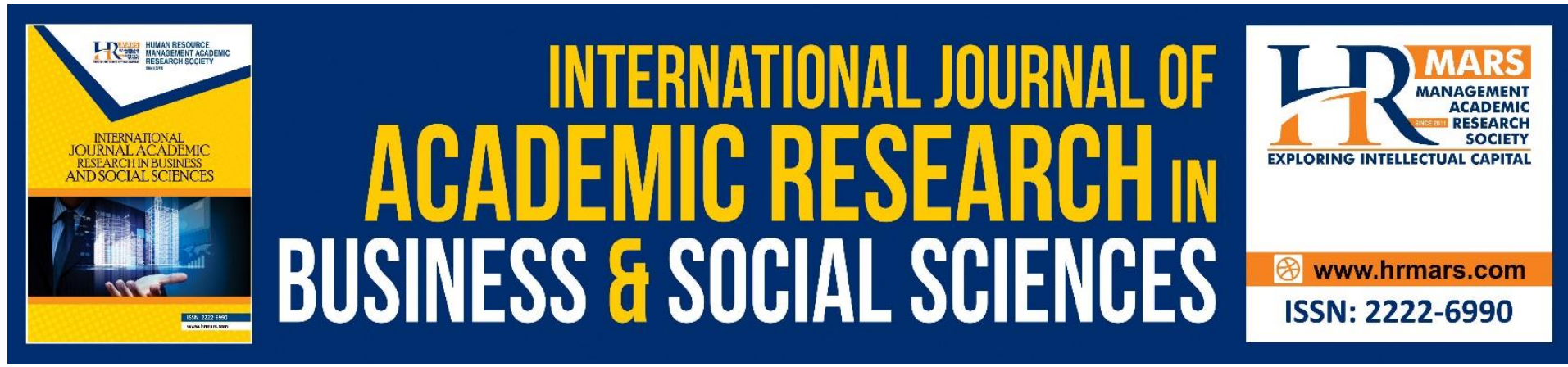

\title{
Exploratory Factor Analysis in Teacher Questioning Elements for Critical Thinking among form 4 Students in Some Selected Schools in the State of Sarawak
}

\author{
Arshad Jais ${ }^{1}$, Noraffandy Yahaya ${ }^{2}$, Nor Hasniza Ibrahim³ \\ Nazeri Bin Mohammad ${ }^{4}$ \\ ${ }^{1}$ Learning Sector, Sarawak State Education Department, ${ }^{2 \& 3}$ Faculty Of Humanities and Social \\ Sciences, University Of Technology Malaysia, ${ }^{4}$ Department of Foreign \& International \\ Cooperation, Aminudin Baki Institute, Genting Highland Branch, Pahang. \\ Email: arshadjais@ymail.com
}

\begin{abstract}
Teacher questioning elements for critical thinking is crucial to ensure the process of teaching and learning. It is dependent on the teacher's ability and capability to master questioning techniques. Questioning skills are not just about acquiring information, rather they are meant to help build a positive communication climate and foster mutual understanding and cooperation between teachers and their students. This study aimed to examine the elements of teacher questioning for critical thinking. Early evidence of the validity of the teacher questioning element for critical thinking was obtained through Exploratory Factor Analysis (EFA). Based on the EFA procedure, the study used principal axis factoring and varimax rotation. This study was a fully quantitative study which used a survey method employing a questionnaire as the study instrument. A total of 147 students were involved as respondents in this study. Data was analysed descriptively using Cronbach's Alpha reliability test and Exploratory Factor Analysis (EFA). There were 3 respondents who were excluded due to outliers in the normality analysis. The normality results achieved showed a Cronbach's Alpha value of 0.874 , well beyond 0.60 . The results of the exploratory factor analysis showed three factors which Eigen values were greater than 1.0. A KMO's (Kaiser-Meyer-Olkin's) value of 0.954, higher than 0.6, indicates that the items in the teacher questioning element variable for critical thinking were sufficient to be interrelated. Mean while, the Bartlett Test was significant (Chi Square $=10295.506, p<0.05$ ). No items were excluded and all values of loading factor obtained exceeded 0.50 , the minimum value for new items. The results of the study indicates that, the EFA has integrated teacher questioning element factors for critical thinking. From the result obtain, teachers are encouraged to master their critical thinking skills inspite of the questioning technique alone.Therefore, this study provides a platform for empirical research and further causal relationship studies in the future.
\end{abstract}


Keywords: Exploratory Factor Analysis, Teacher Questioning, Critical Thinking and Form 4 Students

\section{Introduction}

The field of education today is no longer about merely providing students with basic knowledge and skills. In fact, one of its important aspects these days is effective communication, in the form of asking and questioning activities. Asking and questioning skills are not intended only to get information, rather to help us build a more positive communication climate and foster mutual understanding and cooperation with each other. This is because critical thinking has been widely discussed by many scientists especially among educators. It is one of the two aspects of the study of neuroscience; critical and creative thinking. These two aspects of the study of neuroscience are part of the cognitive operations used by humans to find meanings. Therefore, the selection of elements in teacher questioning during Learning and Facilitation is expected to evoke interactions between teachers and students more effectively, where the former will ask questions related to the content of the lesson and the latter are required to provide appropriate responses.

Teachers' skills to diversify questioning techniques will be able to help the teaching and learning process to be implemented better and more effectively (Arnaud, 2020). In this context, quality teachers are a vehicle to implement education more effectively in producing human capital who are knowledgeable and equipped with various skills to face current and future global developments and challenges (Ron \& Sherman, 2019; Nazeri \& Ruhizan 2015). Students are expected to be able to think creatively and critically, be forward-looking as well as be able to compete competitively in the global market (Ritchie \& Tucker-Drob, 2018; Mohd Sazali, 2015; Nazeri \& Ruhizan, 2015). The role of teachers is important in determining that, the process of this technique can be implemented smoothly and effectively (Cardoso \& Almeida, 2014). As far as teaching techniques are concerned, most focus is given on the achievement of the teachers, particularly in terms of the ways they optimize the teaching materials provided, as well the measures taken. Teachers become the focus of their students since they themselves are responsible for determining the success of their planned teaching and learning process (Nazeri \& Ruhizan, 2015). Subject teachers can play an important role in choosing the most suitable teaching method, according to the level and abilities of their students (Zanaton, 2011).

Questioning techniques and methods are certainly something that should be used thoroughly by teachers to be successful in carrying out the teaching and learning process (Ron \& Sherman, 2019). The type of questions asked and posed to the student will later be an important element that can influence the the student's thinking ability (Ritchie \& TuckerDrob, 2018). A well-managed questioning strategy is expected to encourage students to be continuously aggressive in exploring knowledges related to the content of the lessons from various disciplines of science expected to contribute towards producing a generation of Ulul Albab. Focused questions to be posed by teachers should be able to test and evaluate the teaching content delivered in an effective teaching and learning process (Cardoso \& Almeida, 2014). 


\section{Problem Statement}

The effective use of questions in the teaching of form four Chemistry is necessary to generate students' rational thinking in addressing problems inherent in Higher Order Thinking Skills (HOTS). This is because, the type of questions and questioning techniques are among the factors which are helpful for students to make assessments, provide views, generate critical and creative thinking to achieve abilities and evaluate their achievements in learning (Sazali, 2015; Zanaton, 2011). This can also stimulate students' critical thinking about things they learned in the learning sessions conducted (Arnaud, 2020). In order to familiarize students with such questions, teachers should always give questions in the form of Higher Order Thinking Skills (HOTS). The more HOTS questions are asked, the broader a student's level of thinking will become (Ron \& Sherman, 2019).

The diversity in questioning techniques posed by teachers and the use of different levels of question are important to encourage critical thinking among students in the school. It is recommended that, the questions to be asked comprise both easy or low level questions and difficult or high level questions. However, the use of questioning techniques is to digest thoughts. A question which often arises is about the teachers' questioning element for students' critical thinking. This is because the questions are posed to analyse, synthesise and evaluate skills of the students and provide training for them to communicate (Mohd Sazali, 2015). At the same time, the education system in Malaysia also needs to adapt to the aspirations of the Malaysia Education Blueprint 2013-2025. Therefore, the validity of the instrument needs to be done, because the findings of the study which have high values indicate that, the facts or evidence are able to provide accurate justification. An evaluation tool is valid when the construction of the tool meets or fulfils the functions and objectives of its construction.

\section{Research Objective}

This study aimed to examine the instrument for measuring a reliable construct of teacher questioning element for critical thinking among form four students in the state of Sarawak.

\section{Research Questions}

Does the instrument for measuring the construct of teacher questioning element for critical thinking among form four students in Sarawak meet the requirements of Exploratory Factor Analysis (EFA) and is it reliable?

\section{Literature Review}

Various studies related to $21^{\text {st }}$ century skills have been published to explain the four abilities in the 21st century, namely lifelong learning, problem solving, self-management and teamwork. Meanwhile, the Partnership for 21st Century Skills states that, student outcomes and support systems include living skills and career, learning skills and innovation (critical thinking, communication, collaboration and creativity) as well as information, media and technology skills.

To face the increasingly fierce global competition in an innovation-driven economic environment, the MOE has placed emphasis on Higher Order Thinking Skills (HOTS) in the schooling system. The implementation of HOTS in the schooling system uses a comprehensive and systemic approach that includes seven elements, three main elements namely 
curriculum, pedagogy and assessment, and four supporting elements, in the form of cocurriculum, community and private support, resources and capacity building (Nazeri et al., 2015 ).

Critical and Creative Thinking Skills (KBKK) were introduced in the National Curriculum in 1994 through KBSR and KBSM. Meanwhile, the Primary School Standard Curriculum (KSSR) was introduced in 2011 as an initiative to strengthen and empower thinking skills by emphasizing on reasoning skills. Various thinking skills have been integrated for the purpose of making comparisons and evaluations in problem solving.

Thinking skills need to be based on the values inherent in the students themselves to solve problems and make appropriate decisions. Students who practise their values in a sustainable manner are able to display a noble character, high personality and perform their responsibilities as well as making meaningful contributions to their family, society and the country. Such values include spirituality, humanity, patriotism, integrity, responsibility and unity.

\section{Research Methodology}

Prior to data analysis, the validity and reliability of the data used were tested using Normality Estimation Analysis and Exploratory Factor Analysis (EFA), respectively. EFA was conducted to determine the suitability of the items measuring the acceptance of the developed student application, while Cronbach's Alpha was carried out to determine the validity of the questionnaire instrument. Furthermore, the construct validity of this study instrument was performed by performing exploratory factor analysis (EFA). The factor analysis approach determines the theoretical characteristics and the number of samples required. In general, Kline (2016) argued that, this procedure supports the sample heterogeneity that makes it possible to estimate accurately between item populations.

In this study, EFA was implemented to clarify the meaning of each construct (Rosseni, 2014), and to summarize the interrelated variables by reducing the number of items in each construct so that the remaining items in those constructs could increase the value of variance and beliefs as well as tracing the structure of relationships between items that make up construct dimensions. In other words, it demands adequate representation of respondents at all levels of characteristics which will produce feasible factors. For this reason, the study used quota sampling, a purposive sampling technique. This study used a cross -sectional survey method which determined the sampling strategy and data collection technique as well as validation process based on a factor analysis approach (Reise et al., 2000).

Exploratory factor analysis (EFA) is intended for item reduction while obtaining the best factor structure (Hair et al., 2010). Results of KMO test revealed multicollinearity. If the same correlation value exists between two or more items, those items measure the same aspect. KMO test helps the researcher in terms of identifying whether the items are suitable or unsuitable for performing factor analysis. In this study, the EFA procedure used a principal axis factoring for factor extraction and varimax oblique rotation. Oblique rotation is used to extract psychological latent factors that are theoretically correlated with each other. The extracted loading was set to 0.50 for a simple interpretation of the factors for item selection purposes. The development of indicators or items is intended to capture the manifestations 
of teacher questioning elements for critical thinking as indicated by the indicators selected in each factor. The proposed dimensions and factors are represented by a number of indicators or potential items supported by previous studies, rather than being self-developed to ensure their inclusion in the initial item group. The items were created through a special framework from literature reviews of previous studies.

\section{Findings}

\section{Normality, Item Analysis and Communality}

Table 2 shows normality (skewness and kurtosis), item analysis (corrected item-total correlation) and communality of teacher questioning elements for critical thinking. The EFA procedure for this study aimed to uncover latent factors in this example of school leaders. Items in the teacher questioning and critical thinking elements were subjected to item analysis using reliability analysis. The initial reliability was 0.91 , which indicates a high internal consistency of the instrument. However, the main concern in this method is the items corrected to the total correlation index for each item which contributes to the overall reliability of the instrument. Items corrected to total correlation showed a minimum value of 0.04 and a maximum value of 0.63 . Only SLT2 items are below the threshold value of 0.30 (Field, 2009). Communality was found to be in the range of 0.04 to 0.82 , where three items were less than 0.30 (Kline, 2016). Therefore, all these three items were recommended to be excluded.

\section{Exploratory Factor Analysis (EFA)}

A series of EFA was carried out accordingly. The application of oblique rotation through Varimax rotation can provide an early indication whether the respective data has multicollinearity problems (Kline, 2016). The correlation matrix between the factors of the final factor solution will satisfy this goal. The varying values of the factors are from a minimum of 0.11 to a maximum of 0.64 . The maximum range of construct correlation is below the threshold value of 0.90 , indicating no multicollinearity problem. On the other hand, the majority of correlations were found to be higher than 0.30 , explaining the appropriateness of using Varimax oblique rotation, which reflects the nature of psychological constructs (Kline, 2016). This will allow for as many factors needed to represent each of the original variables. In the last round of the EFA, the total quadratic loading extraction from the eight-factor solution in Table 1 managed to capture $60 \%$ of the total variance explained which is respectable enough for the newly conceptualized multi-dimensional construction.

Meanwhile, the remaining $40 \%$ of the variance could not explain the latent construct of the teacher questioning element for critical thinking. The sample adequacy measure, Kaizer-Mayer-Olkin (KMO) was 0.90 , indicating an adequate number of EFA samples (Kline, 2016). This value is expected, because of the high ratio of participants to the variables, namely, 5: 1 . The Bartlett Sphericity test is significant $(X 2=9062.095, p=.000)$ with $p$ below 0.05 (Kline, 2016). These results indicate the adequacy of sampling that will yield meaningful factors from the current data. The Diagonal Anti-Image Matrix of the current data index far exceeds the cutoff correlation value of 0.50 with a range between 0.85 and 0.96 (Hair et al., 2010). 
Table 1

The number of variances is explained from 6 variable factors.

\begin{tabular}{|c|c|c|c|c|c|c|}
\hline \multicolumn{3}{|c|}{ Initial Eigenvalues } & \multicolumn{4}{|c|}{ Extraction Sums of Squared Loadings } \\
\hline \multicolumn{7}{|c|}{ Factor } \\
\hline 1 & 1.993 & 5.694 & 50.524 & 1.673 & 4.779 & 47.584 \\
\hline 2 & 1.626 & 4.647 & 55.171 & 1.209 & 3.454 & 51.038 \\
\hline 3 & 1.335 & 3.815 & 58.985 & .964 & 2.754 & 53.792 \\
\hline 4 & 1.255 & 3.587 & 62.573 & .810 & 2.314 & 56.106 \\
\hline 5 & 1.185 & 3.387 & 65.960 & .791 & 2.261 & 58.367 \\
\hline 6 & 1.025 & 2.989 & 68.888 & .585 & 1.670 & 60.038 \\
\hline
\end{tabular}

Note: For EFA, Total Variance is expressed in bold numbers.

Confirmatory Factor Analysis is a testing method to see how the variables represent the constructs in the research. Researchers need to know the number of factors and variables which carry weights to those factors before performing a Confirmatory Factor Analysis. Confirmatory Factor Analysis also has the strength to access construct validity in the resulting measurement model, apart from its function as a determinant of the measurement of variables to the respective constructs. Through it, construct validity is the extent to which a constructed item measures the latent construct which the item is supposed to measure.

Table 2 Standardized Loading and Squared Multiple Correlations (SMC): Second Order Measurement Model - Critical Thinking.

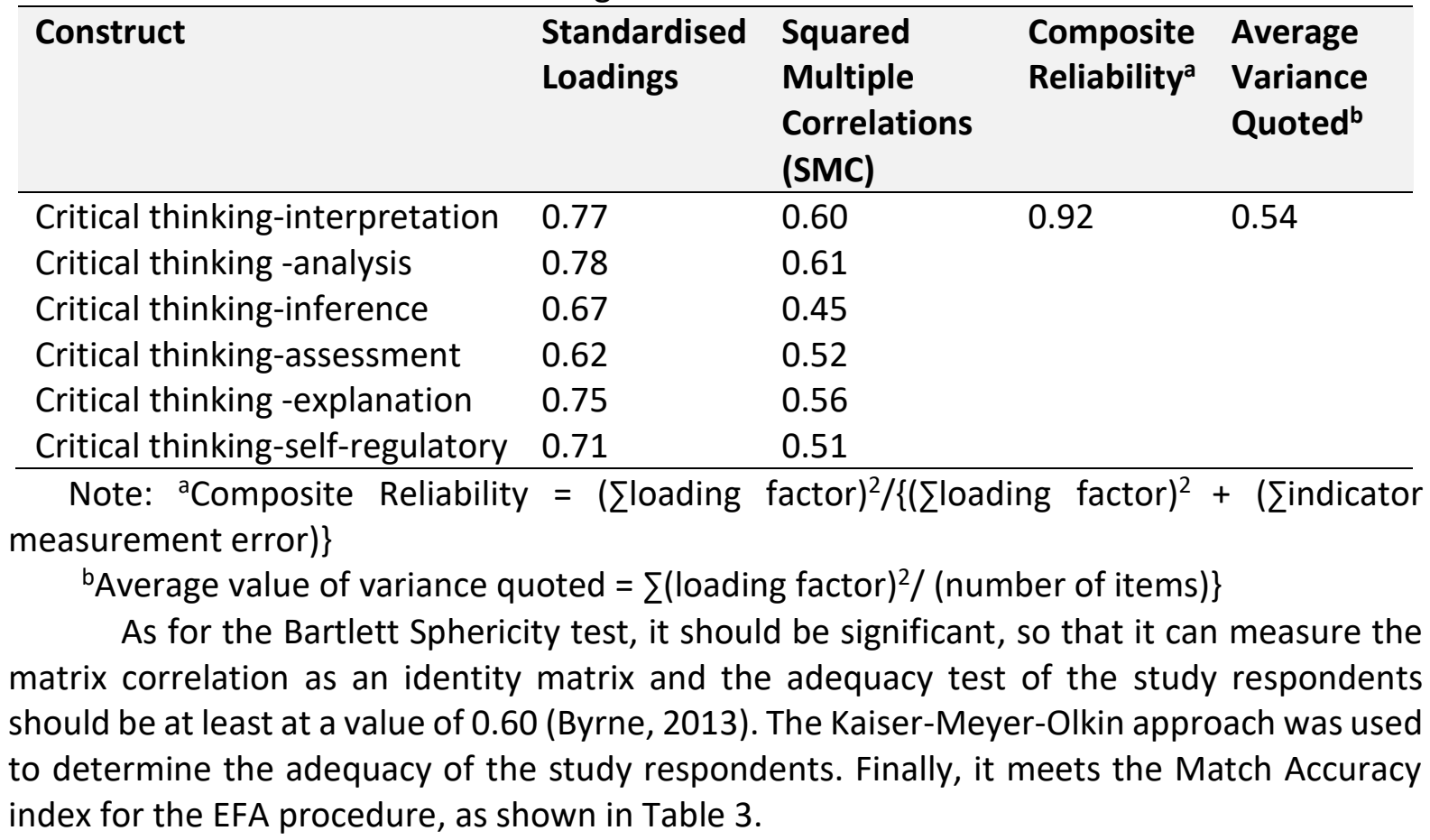


Table 3 Match Accuracy Model using Fit Index for Exploratory Factor Analysis (EFA).

\begin{tabular}{lc}
\hline Indices of EFA Model & $\begin{array}{l}\text { Recommended } \\
\text { values* }\end{array}$ \\
\hline Sphericity Bartlett Test / $\chi^{2}$ (Sig. <0.05) & $<0.05$ \\
Adequacy of Respondents / Kaiser-Meyer-Olkin (KMO) & $\geq 0.80$ \\
Loading factor & $\geq 0.50$ \\
Communality & $\geq 0.30$ \\
Eigenvalue & $\geq 1.00$ \\
Percentage of variance contribution towards factors & $\geq 3.00$ \\
\hline Sources: Hair et al., (2014), Bryne (2010b), Harrington (2009) dan Ullman (2007).
\end{tabular}

The above procedure was repeated several times until a construct with its own item was formed (Brown \& Moore, 2012), and this involves a cycle of item iterations (Byrne, 2013). Following this, a separate analysis was conducted on the data obtained from pilot studies I and II, based on the constructs and sub-constructs of the study to obtain item score correlation values, along with total scores and corrected item score correlation values with the total scores (corrected item-total correlation). The existence of an item in this construct is said to be valid when it has an Item-Total Correlation value exceeding 0.50 and its Interitem correlation exceeding 0.30 .

As is common practice, theoretical assertions will determine the number factors to be retained. In this study, efforts were taken to retain as many factors as possible in order to maintain the adequacy of the factors in the questioning element for critical thinking. This is in line with the needs of global competencies, where every student needs to master a variety of thinking skills, including problem solving, reasoning and creative and innovative thinking. The implementation of Learning and Facilitation which gives less emphasis to these skills causes students to be less able to apply knowledge and think creatively in daily life. Finally, the researchers decided to include all the extracted factors in this component with a number of items corresponding to the theoretical and practical reasons with an overall internal consistency of 0.93 . To conclude the procedure, the overall internal consistency of the final factor structure was 0.93 . The most important thing was that, the final structure of the factors for the teacher questioning element for critical thinking among form four students of selected schools in Sarawak obtained its dimensions and showed evidence of the validity of the initial construct by having important psychometric characteristics. The results of the above analysis led to the formation of the final model shown in Figure 1.

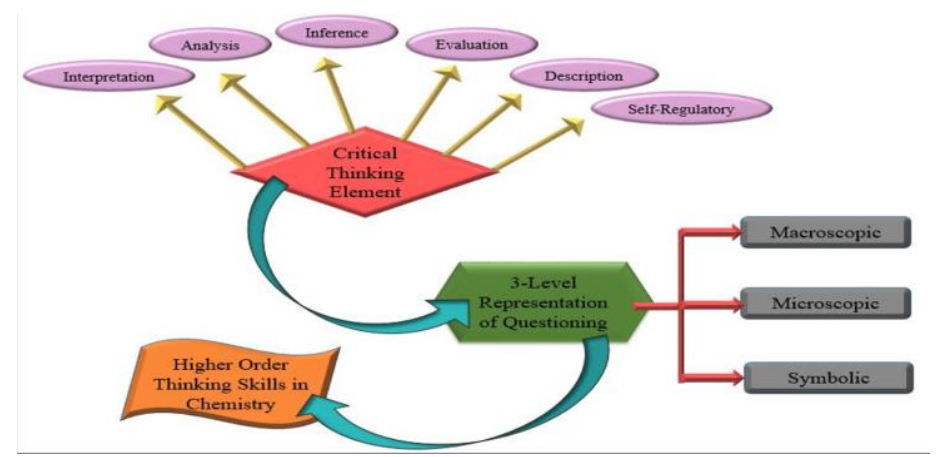

Figure 1: Final model of teacher questioning element for critical thinking among form four students of selected schools in Sarawak. 


\section{Discussion}

For the purpose of consolidating construct development in this instrument, EFA analysis is very important. This was done separately from the actual data used, i.e. by using an improved questionnaire based on the recommendations made in the study by Hair et al. (2010) and Bryne (2010). The varimax rotation method is performed on items to produce meaningful orthogonal (uncorrelated) factors that can be interpreted more accurately. The questions prepared should be varied, aimed to ensure different responses among the students (Mohd Sazali, 2015).

One conventional way to categorize a question is by looking at the frequency of its use, according to the level of the cognitive domain. This means, the questions should be able to be well categorised. For examples; i. knowledge, where questions in the form of knowledge are those which can digest simple memories. The category of this type of question should be selected by the teacher, especially when presenting a new topic or idea to the students; ii. Comprehension, where, after being exposed to a concept and knowledge, students should be ask questions which focus on their understanding. This means that, teaching and learning activities will take place in the dimension of comprehension or comprehension activities; iii. Applications, where questions asked involve the use of information given to the students. Application questions are intended to help students apply knowledge through the information delivered during teaching and learning activities; iv. Analysis, where the characteristic of analytical questions is that the function of the questions is to separate ideas. At a higher level, students will be provided with analytical questions and teachers need to be careful so that students can follow the learning content and use all the skills taught to them; v. synthesis, where synthesis questions are questions which can help students create new ideas and integrate them through the initial information provided to them. A high level of skills are required to enable teachers to guide their students, until they are able to synthesise information; vi. Evaluation, where at the highest level, questions in the form of evaluation will be given to students. This requires students to be able to make justifications and also defend them.

\section{Conclusion}

This PCA procedure can be used, since the main purpose of EFA is to identify all constructs which exist in the selected variables used in the subsequent analyses. Through this procedure also, all uncorrelated items need to be removed until a single construct is formed in a single questionnaire. Exploratory Factor Analysis (EFA) in this study aimed to enable the measurement of teacher questioning element constructs, more accurately and meaningfully in the context of teacher questioning techniques in Chemistry in Sarawak secondary schools. Hence, there is a need to examine teachers' questioning practices for students' critical thinking, by implementing EFA, so that all items involved are loaded based on pre-determined factors.

This is because, the elements and techniques of questioning and answering are the oldest and the most popular techniques used in the field of education. The selection of these techniques in teaching and learning can produce effective interactions between teachers and students. Furthermore, the development of students' minds is assisted by planned activities such as exploration, research and project-based activities. This experience will provide an opportunity for them to prove their potential and self-appreciation. 
This technique is implemented by means of teachers asking questions related to the content of the lesson and students are required to respond accordingly. The success in the use of this technique in teaching and learning depends on the ability of the teachers to master the questioning technique. The involvement of students in teaching and learning sessions $(P d P)$ is a very important thing to take into account. If their involvement is unsatisfactory, indirectly the PdP objectives cannot be achieved well. Most importantly, this instrument can be applied in empirical research and causal relationships studies in various fields in the future.

\section{References}

Arnaud, C. H. (2020). Questioning the value of general chemistry labs. C\&EN Global Enterprise, 98 (18), 17-19. https://doi: 10.1021/cen-09818-feature1.

Brown, T. A., \& Moore, M. T. (2012). Confirmatory factor analysis. Handbook of structural equation modeling, 361-379.

Bryne, B. M. (2010a). Modeling With AMOS: Basic concepts, application and programming. Second Edition. Routledge: New York.

Bryne, B. M. (2010b). Structural Equation Modeling with AMOS: Basic Concepts, Applications and Programming. New Jersey: Lawrence Erlbaum Associates Publishers

Byrne, B. M. (2013). Structural equation modeling with AMOS: Basic concepts, applications, andprogramming. 2nd's Edition. New York: Routledge

Cardoso, M. J., \& Almeida, P. A. (2014). Fostering Student Questioning in the Study of Photossyntesis. Procedia-Social and Behavioral Sciences, 116, 3776-3780. https: //doi.org /10.1016/ j.sbspro.2014.01.840

Hair, J. F., Black, W. C., Babin, B. J., \& Anderson, R. E. (2010). Multivariate Data Analysis: A Global Perspective. Upper Saddle River, New Jersey: Pearson Edition.

Kline, R. B. (2016). Principles and practice of structural equation modeling. 4th's Edition. New York: The Guilford Press.

Sazali, M. K. (2015). A snapshot of Higher Order Thinking Skills in few secondary schools in Penang. Advances in Language and Literary Studies. 6 (5), 67-72. https://doi: 10.7575 /aiac.alls.v.6n.5p.67

Nazeri, M., Ruhizan, M. Y., \& Ana. (2015). Creative Teaching in Design and Technology Curriculum: Using Structural Equation Modeling. Procedia-Social and Behavioral Sciences. 240-246.https:// doi: 10.1016/j.sbspro.2015.08.146

Ritchie, S. J., \& Tucker-Drob, E. M. (2018). How Much Does Education Improve Intelligence? A Meta-Analysis. Psychological Science, 29 (8), 1358-1369.

Ron, B., \& Sherman, R. (2019). Integrating the Human Element in the Responsible Research and Innovation Framework into Systems Thinking Approaches for Teachers' Professional Development. Journal of Chemical Education 2019, 96, 12, 2700-2703.

Rosseni, D. (2014). Construction \& Modeling of Teaching Systems. Bangi: National University Malaysia, UKM.

Zanaton, I. (2011). The practice of oral questioning of chemistry teachers in teaching and learning electrochemistry. University of Malaya. 